\title{
OVERWEIGHT AND OBESITY IN ITALIAN ADOLESCENTS: EXAMINED PREVALENCE AND SOCIO-DEMOGRAPHIC FACTORS
}

\author{
Myriam Galfo, Laura D'Addezio, Laura Censi, Romana Roccaldo, Deborah Martone \\ Research Centre for Food and Nutrition, Council for Agricultural Research and Economics, Rome, Italy
}

\section{SUMMARY}

Aim: This study aimed to evaluate the prevalence of overweight and obesity derived from measured data of weight and height in a cross-sectional sample of adolescents in the Italian region of Lazio and to analyse their association with different socio-demographic factors.

Methods: The study was conducted in a representative sample of 15-16-year-old adolescents recruited in secondary schools between December 2011 and May 2012. 369 adolescents were investigated. Body weight, height and waist circumference were measured. The BMI of each subject was calculated, and the prevalence of overweight and obesity was determined by age and sex using the IOTF reference values and WHO growth standards. Waist circumference/height ratio (WC/Ht) was calculated and the subjects were classified using the cut-off of $0.5: \mathrm{WC} / \mathrm{Ht} \geq 0.5$ and $\mathrm{WC} / \mathrm{Ht}<0.5$. Selected socio-demographic characteristics were assessed via questionnaire.

Results: The percentages of overweight and obesity were high, $15.4 \%$ and $7.9 \%$, respectively, with significant difference between males and females ( $19.1 \%$ vs. $12.6 \%$ for overweight and $11.1 \%$ vs. $5.3 \%$ for obese) using the IOFT reference. The ratio WC/Ht $\geq 0.5$ was observed in $12.7 \%$ of the sample (all the obese and $29.8 \%$ of the overweight subjects). Multiple logistic regression analysis indicated that gender, school municipality, mother's employment status, and family structure had a significant effect on ponderal status (overweight/obesity vs. normal weight).

Conclusion: These findings show a high prevalence of body weight excess associated with socio-demographic factors in the Italian sample investigated, and the need for effective public health interventions to combact obesity with particular attention to disadvantaged adolescents.

Key words: adolescents, obesity, overweight, prevalence, socio-demographic factors

Address for correspondence: M. Galfo, Council for Agricultural Research and Economics, Research Center for Food and Nutrition, Via Ardeatina 546, 00178 Rome, Italy. E-mail: myriam.galfo@crea.gov.it

http://dx.doi.org/10.21101/cejph.a4367

\section{INTRODUCTION}

The World Health Organization (WHO) considers childhood obesity to be a major public health concern (1). During the two recent decades, high prevalence rates of overweight and obesity particularly among children and adolescents have become a concern in both the developed and developing countries (2-5). The main contributing factors in the increasing prevalence of overweight and obesity are difficult to pinpoint, but it is believed to be a complex interaction of the environmental, genetic and lifestyle behaviours (6).

Overweight and obesity are among the most contributing predisposing factors to the overall burden of disease worldwide (7, 8). Presently, more than $30 \%$ of children and adolescents aged 2-19 years are classified as overweight or obese with a body mass index (BMI) higher than the 85th percentile of the Centers for Disease Control and Prevention growth charts (9, 10). In Europe, southern countries tend to have higher children overweight and obesity prevalence $(20-35 \%)$ than northern ones $(11,12)$. Also within the same country, the prevalence and trends of overweight and obesity may be not homogeneous according to different geographic regions (13). In Italy, the Health Behaviour in Schoolaged Children (HBSC) survey has shown a high prevalence of overweight/obese children, greater in males than in females, that decreases in both genders with age, ranging from $28.1 \%$ in males and $18.8 \%$ in females of 11 years to $25.2 \%$ in males and $11.9 \%$ in females of 15 years (14). A gradient North-South in Italy was also observed, especially for obese boys (15). However, these results from self-reported weight and height could underestimate the actual situation in Italy. Moreover, there is a need to study more in-depth the life environment factors to implement effective interventions of healthy lifestyles promotion.

The aim of the present paper was to evaluate the prevalence of overweight and obesity derived from measured data of weight and height in a cross-sectional representative sample of adolescents in the Italian region of Lazio and to analyse their association with different socio-demographic factors.

\section{MATERIALS AND METHODS}

\section{Subjects}

The present cross-sectional study “ALIADO”, performed on a representative sample of adolescents aged $15-16$ years, was part of a larger project called "REGALIM", promoted by the Ministry 
of Agriculture, Food and Forestry (MAFF). Several aspects were studied including their environmental and food habits, lifestyle and physical activity. The adolescents investigated were attending the second class of randomly selected public and private secondary schools in the region of Lazio (Fig. 1), according to a list provided by the Regional Education Office for Lazio. Cluster sampling was performed according to the World Health Organization cluster survey methodology (16) with classes as the units of sampling. The number of subjects to be studied was calculated taking into account an expected prevalence of overweight and obesity of $30 \%$, a desired precision level of $5 \%$, and a design effect of 2. In total, 438 students (203 males and 235 females) from twenty-one secondary school classes were recruited. Participation in the project was quite high (86.1\%), especially considering the significant amount of collaboration needed from families, teachers and subjects; however, $1.7 \%$ of the total of adolescents were absent from school on the day of the survey and it was not possible to recover them afterwards. The final participation rate was $84.4 \%$. Four subjects were excluded from the study because they were older than 18 years. Overall, 369 adolescents (162 males and 207 females) were investigated in the study.

Data collection was performed between December 2011 and May 2012. The study was in compliance with the Ethics Committee of the National Research Institute on Food and Nutrition. Only adolescents with a consent form signed by a parent or legal guardian were included in the sample.

\section{Anthropometric Measurements}

Weight, height and waist circumference measurements were carried out by two trained and standardized observers, according to WHO recommendations (17). Height was measured to the nearest $0.1 \mathrm{~cm}$ by a stadiometer SECA 214 (Hamburg, Germany), with the subject without shoes, standing up, weight being equally distributed on feet, with the head in the Frankfurt plane and the

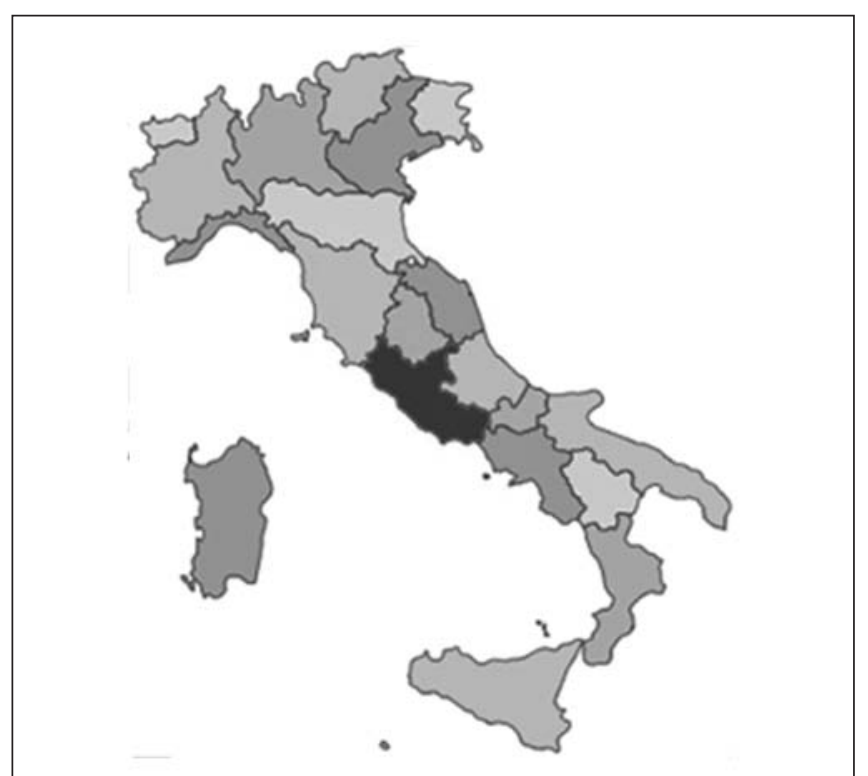

Fig. 1. Geographical position of secondary school classes selected in the region of Lazio. back of the head, buttocks and heels (if possible) in contact with the vertical board. Weight was measured to the nearest $50 \mathrm{~g}$ by an electronic scale SECA 872TM (Hamburg, Germany), with the subject in fasting condition (or after a light breakfast), and after empting the bladder. Waist circumference was measured to the nearest $0.1 \mathrm{~cm}$ in triplicate by a metric tape (SECA 201). The average of three measurements was used. The measurements were carried out at school in the morning, one adolescent at a time, in a quiet room, ensuring privacy and confidentiality for each youth. Body Mass Index (BMI) was calculated as the weight in kilograms divided by the square of the height in meters $\left(\mathrm{kg} / \mathrm{m}^{2}\right)$. In order to classify the ponderal status of the adolescents, BMI values were compared with those of the international reference tables specific for age and sex, suggested by the International Obesity Task Force (IOTF) (18). According to the suggestion of the European Childhood Obesity Group (ECOG) we also used the WHO definitions $(19,20)$ to evaluate the prevalence of overweight and obesity (21). However, for the analyses of association between overweight/obesity and the variables investigated, the IOTF cut-offs were used (18).

Waist circumference/height ratio (WC/Ht) was calculated as it is a good index for selecting children with the highest cardio metabolic risk $(22,23)$, the subjects were classified using the cut-off of 0.5 : WC/Ht $\geq 0.5$ and $\mathrm{WC} / \mathrm{Ht}<0.5$ (24).

\section{Socio-demographic and Parents' Data}

Household socio-demographic information about age, gender, type of school, parents' education and employment, and family structure was self-reported by the adolescents.

The type of school was classified as "high school" and "technical institute" or "professional training". The municipality of the school location was classified in metropolitan area (municipalities inside of the metropolitan area and municipalities around the metropolitan area) and non-metropolitan area (municipalities up to more than 50,000 inhabitants) according to the standard classification of the National Institute of Statistics (ISTAT, 2010). Parents' educational level was classified in three categories: less than middle school, high school, university. Mothers' employment status was categorized as "employed" and "homemaker". The number of parents living in the household was considered as the indicator of the family social structure.

\section{Statistical Analysis}

Statistical analyses were performed using the statistical packages Statistica for Windows version 8.0 (StatSoft, Inc., Tulsa, OK, USA) and SAS, version 9.2 (User's Guide, Cary, NC, USA: SAS Institute Inc, 2008) for logistic regression analysis. Means and standard deviations were reported for continuous variables. Associations between ponderal status and each categorical variable were tested by contingency tables and Pearson's chi-square test. A multiple logistic regression model, backward stepwise method, was employed to evaluate the association of selected socio-demographic factors and overweight/obesity status (dependent variable). Analyses were conducted without (unadjusted) and with (adjusted) covariates. For all the tests a p-value $<0.05$ was considered to be statistically significant. 
Table 1. Study sample characteristics (means \pm standard deviation)

\begin{tabular}{|l|c|c|c|}
\hline & $\begin{array}{c}\text { Males } \\
(\mathrm{N}=162)\end{array}$ & $\begin{array}{c}\text { Females } \\
(\mathrm{N}=207)\end{array}$ & $\begin{array}{c}\text { Total } \\
(\mathrm{N}=369)\end{array}$ \\
\hline Age (years) & $15.9 \pm 0.6$ & $15.7 \pm 0.5$ & $15.8 \pm 0.5$ \\
\hline Weight $(\mathrm{kg})$ & $68.5 \pm 15.0$ & $57.8 \pm 10.2$ & $62.5 \pm 13.6$ \\
\hline Height $(\mathrm{cm})$ & $173.9 \pm 6.7$ & $162.0 \pm 6.6$ & $167.2 \pm 8.9$ \\
\hline BMl $\left(\mathrm{kg} / \mathrm{m}^{2}\right)$ & $22.6 \pm 4.4$ & $22.0 \pm 3.6$ & $22.3 \pm 4.0$ \\
\hline Waist circumference $(\mathrm{cm})$ & $77.4 \pm 10.6$ & $70.3 \pm 7.6$ & $73.4 \pm 9.7$ \\
\hline
\end{tabular}

Table 2. Ponderal status of sample according to IOTF and WHO definition

\begin{tabular}{|c|c|c|c|c|c|c|}
\hline & \multicolumn{3}{|c|}{ IOFT } & \multicolumn{3}{|c|}{ WHO } \\
\hline & $\mathrm{n}$ & $\%$ & $95 \% \mathrm{Cl}$ & $\mathrm{n}$ & $\%$ & $95 \% \mathrm{Cl}$ \\
\hline \multicolumn{7}{|l|}{ All samples } \\
\hline Obese & 29 & 7.9 & 5.4-11.2 & 31 & 8.4 & $5.9-11.8$ \\
\hline Overweight & 57 & 15.4 & $12.0-19.6$ & 65 & 17.6 & 13.9-22.0 \\
\hline Normal weight & 260 & 70.5 & $65.5-75.1$ & 268 & 72.6 & $67.8-77.1$ \\
\hline Thinness & 23 & 6.2 & $4.1-9.3$ & 5 & 1.4 & $0.5-3.3$ \\
\hline \multicolumn{7}{|l|}{ Males } \\
\hline Obese & 18 & 11.1 & $6.7-17.0$ & 19 & 11.7 & $7.2-17.7$ \\
\hline Overweight & 31 & 19.1 & $13.4-26.0$ & 36 & 22.2 & $16.1-29.4$ \\
\hline Normal weight & 102 & 63.0 & $55.0-70.4$ & 103 & 63.6 & $55.7-71.0$ \\
\hline Thinness & 11 & 6.8 & $3.4-11.8$ & 4 & 2.5 & $0.7-6.2$ \\
\hline \multicolumn{7}{|l|}{ Females } \\
\hline Obese & 11 & 5.3 & $2.7-9.3$ & 12 & 5.8 & $3.0-9.9$ \\
\hline Overweight & 26 & 12.6 & 8.4-17.9 & 29 & 14.0 & $9.6-19.5$ \\
\hline Normal weight & 158 & 76.3 & $69.9-81.9$ & 165 & 79.7 & $73.6-85.0$ \\
\hline Thinness & 12 & 5.8 & $3.0-9.9$ & 1 & 0.5 & $0.0-2.7$ \\
\hline
\end{tabular}

\section{RESULTS}

Characteristics of the sample are shown in Table 1. Subjects aged $15.8 \pm 0.5$ years had weight $62.5 \pm 13.6 \mathrm{~kg}$, height $167.2 \pm 8.9$ $\mathrm{cm}$, BMI $22.3 \pm 4.0 \mathrm{~kg} / \mathrm{m}^{2}$, and waist circumference $73.4 \pm 9.7$ $\mathrm{cm}$. Table 2 shows the ponderal status of adolescents according to $\operatorname{IOFT}(18)$ and $\mathrm{WHO}(19,20)$ definitions. According to IOFT (18), the percentages of overweight and obesity were $15.4 \%$ and $7.9 \%$, respectively, and significantly differed between males and females (19.1\% vs. $12.6 \%$ for overweight and $11.1 \%$ vs. $5.3 \%$ for obesity). According to the WHO definition $(19,20)$, the rates of overweight and obesity were $17.6 \%$ and $8.4 \%$, respectively, and also in this case there were significant differences between males and females (22.2\% vs. $14.0 \%$ for overweight and $11.7 \%$ vs. $5.8 \%$ for obesity). As expected, a higher prevalence of overweight and obesity was observed in the study sample using the WHO reference $(19,20)$.

The ratio $\mathrm{WC} / \mathrm{Ht} \geq 0.5$ was observed in $12.7 \%$ of the sample, more in males $(16.0 \%)$ than in females $(10.1 \%)$, though not significant. All the obese and $29.8 \%$ of the overweight subjects had this ratio $\geq 0.5$.

Table 3 shows the prevalence of overweight and obesity according to socio-demographic factors. The percentages of overweight and obese adolescents were higher among students from "technical and professional training institutes" compared to those who attended high school (21.1\% and $13.3 \%$ vs. $12.5 \%$ and $5.0 \%, \mathrm{p}<0.001)$. A higher number of overweight and obese subjects were found among adolescents in the non-metropolitan area (19.8\% and $11.5 \%$, respectively) compared to the metropolitan area (12.3\% of overweight and $5.2 \%$ of obese). The prevalence of overweight/obesity decreased with increasing level of parental education, especially mothers' education, although this result was not statistically significant. Rates of overweight and obesity were lower in youth whose mothers were employed than in those whose mothers were homemakers (12.6\% and 6.1\% vs. $20.8 \%$ and $11.7 \%$, respectively), and were significantly lower among adolescents who lived in a dual parent household than those living in a single parent household (13.9\% and 6.8\% vs. $23.7 \%$ and $13.6 \%$, respectively).

Crude and adjusted odds ratios for socio-demographic factors associated with overweight/obesity, obtained from a multiple regression model are shown in Table 4. Gender, school municipality, employment status of the mother, and family structure had a significant effect on ponderal status (overweight/obesity vs. normal weight), whereas the type of school and parents' education level had no significative association, and therefore were excluded from 
Table 3. Prevalence of overweight and obesity of sample according to socio-demographic factors

\begin{tabular}{|c|c|c|c|c|}
\hline & $\begin{array}{l}\text { Under/normal weight } \\
\%\end{array}$ & $\begin{array}{l}\text { Overweight } \\
\%\end{array}$ & $\begin{array}{l}\text { Obesity } \\
\quad \%\end{array}$ & $p$ value \\
\hline \multicolumn{5}{|l|}{ Gender } \\
\hline Male & 69.8 & 19.1 & 11.1 & \multirow{2}{*}{$<0.02$} \\
\hline Female & 82.1 & 12.6 & 5.3 & \\
\hline \multicolumn{5}{|l|}{ Type of school } \\
\hline High school & 82.6 & 12.5 & 5 & \multirow{2}{*}{$<0.001$} \\
\hline Technical/professional training & 65.6 & 21.1 & 13.3 & \\
\hline \multicolumn{5}{|l|}{ School municipality } \\
\hline Metropolitan & 82.6 & 12.3 & 5.2 & \multirow{2}{*}{$<0.01$} \\
\hline Non-metropolitan & 68.8 & 19.8 & 11.5 & \\
\hline \multicolumn{5}{|l|}{ Mother's educational level } \\
\hline Less than middle school & 70.2 & 17.9 & 11.9 & \multirow{3}{*}{0.137} \\
\hline High school & 75.5 & 16 & 8.5 & \\
\hline University & 85.1 & 11.7 & 3.2 & \\
\hline \multicolumn{5}{|l|}{ Father's educational level } \\
\hline Less than middle school & 71.1 & 16.5 & 12.4 & \multirow{3}{*}{0.335} \\
\hline High school & 78.7 & 14 & 7.3 & \\
\hline University & 80.5 & 14.9 & 4.6 & \\
\hline \multicolumn{5}{|l|}{ Mother's employment status } \\
\hline Employed & 81.4 & 12.6 & 6.1 & \multirow{2}{*}{0.119} \\
\hline Homemaker & 67.5 & 20.8 & 11.7 & \\
\hline \multicolumn{5}{|l|}{ Family structure } \\
\hline Dual parent household & 79.4 & 13.9 & 6.8 & \multirow{2}{*}{$<0.05$} \\
\hline Single parent household & 62.7 & 23.7 & 13.6 & \\
\hline
\end{tabular}

Table 4. Odds ratios (OR) and 95\% confidence intervals (CI) from logistic regression analysis showing the association of ponderal status (overweight/obese vs. normal weight) with selected socio-demographic variables ${ }^{a}$

\begin{tabular}{|l|r|r|}
\hline Subjects overweight/obese vs. normal weight & Unadjusted OR (95\% Cl) & Adjusted OR (95\% Cl) \\
\hline Gender & $1.99(1.22-3.25)$ & $2.03^{\star}(1.19-3.46)$ \\
\hline Males vs. Females & $2.15(1.32-3.5)$ & $2.00^{\star}(1.17-3.44)$ \\
\hline School municipality & \\
\hline Non-metropolitan vs. metropolitan & $2.10(1.28-3.46)$ & $1.95^{\star}(1.12-3.37)$ \\
\hline Mother's employment status & & \\
\hline Homemaker vs. employed & $2.20(1.19-4.10)$ & $2.30^{\star}(1.14-4.64)$ \\
\hline Family structure & & \\
\hline Single-parent vs. dual-parent &
\end{tabular}

avariables are mutually adjusted; *p value $<0.05$

the model. The results show that males were twice as likely to be overweight/obese than females, adolescents who attended school in non-metropolitan areas were twice as likely to be overweight/ obese than those who attended school in metropolitan areas; subjects whose mother was homemaker were almost twice (1.95 times) as likely to be overweight/obese than those whose mother was employed; adolescents living in a single parent household (in most of the cases they lived with their mother) were 2.30 times more likely to be overweight/obese than those living in a dual parent household.

\section{DISCUSSION AND CONCLUSION}

A total of $23.3 \%$ of the adolescents investigated had excess weight according to the IOTF criteria (18) and $26.0 \%$ according to the WHO criteria (19-20). This problem was more marked in males, in adolescents attending technical and professional training schools, in those who attended schools located in non-metropolitan areas, and in those living in single or no-parent families.

As expected, the prevalence of body weight excess was higher than that observed in the HBSC international survey (14) of $18.3 \%$ 
overweight including obesity (25), evaluated by the IOTF criteria (18) from self-reported data in the same Italian region (Lazio) and similar age group. The difference was very high for the prevalence of obesity (7.9\% in our sample, vs $1.5 \%$ in the HBSC survey). Also in the HBSC survey a clear difference in the prevalence of overweight and obesity by gender was found, with more boys overweight and obese than girls.

Waist circumference (WC) and the WC/Ht ratio are simple measures of central obesity associated with visceral fat and the risks of cardio-metabolic disorders $(26,27)$. These indexes have been recently recommended as part of anthropometric measurements to identify and monitor obesity in paediatric general practice $(28,29)$. We applied the WC/Ht cut-off point of 0.5 (24) and we found that more than one third of the overweight subjects and all the obese resulted with abdominal obesity.

Adolescents who lived in single parent families presented a higher prevalence of overweight and obesity and had more than twice the risk of being overweight or obese. This is in agreement with previous studies that have shown a higher obesity rate in single parent families (30-32). It has been hypothesized that this association is attributable to a lower income, with choice of cheaper and less healthy food and less time available to support physical activity as a consequence (33).

Our study also indicated that mother's employment status is an important factor for predicting overweight and obesity. In fact, the results showed a higher prevalence of overweight/obesity in those adolescents whose mothers were housemakers compared to those whose mothers were employed. These findings contrast with previous studies on younger children, which pointed out the opposite effect $(34,35)$ but are in agreement with the results of the Italian survey conducted on younger children (36).

The stronger association found between overweight/obesity and mothers' employment rather than between overweight/obesity and parental education also contrasts with the results of many previous studies (37), which have shown that parental education, particularly mothers', is the strongest socioeconomic predictor of child obesity. This may be partly because parental education has the benefit of being relatively stable; it does not fluctuate according to transient life events as income or occupation. Education has also the advantage of being a modifiable factor and it has been suggested that it provides a possible route for family intervention to reduce obesity risk (38), although it is not clear how far education interventions directly affect lifestyle risk factors for child's overweight. The present results may be a consequence of the different mechanisms that are involved in the causal relationships where socioeconomic indicators influence obesity and vice versa, as proposed by Sobal (39). Although an inverse association between overweight/obesity and parental education exists, it is possible that in the social context represented by our sample other stronger factors prevail as determinants of overweight and obesity status in adolescents. According to Sobal, education influences knowledge and beliefs, occupation influences lifestyle and shared values, and income relates to access to resources. In our context it is possible that income and access to resources are more important for healthy lifestyle than knowledge and beliefs.

When considering the location of the schools, we observed a higher prevalence of overweight and obesity in those located in non-metropolitan rather than in metropolitan areas. Our results were similar to those of a previous study conducted on a sample of Swedish schoolchildren, in which there was a clear urban-rural gradient with a higher prevalence of overweight in rural compared with urban areas, however, as for the obesity rate the urban-rural gradient was observed in boys only (40).

This study has some limitations. The cross-sectional study design does not allow analysis of cause-and-effect relationships and does not include adolescents out of schools although we examined the age group that has an obligation to go to school in Italy. The strengths of our study lie in the sample representativeness of the studied population, in the high participation rate and in the assessment of the prevalence of overweight and obesity by measured weight and height. We also used WC/Ht as an index of cardio-metabolic risk.

In conclusion our study showed a high prevalence of overweight and obesity from measured weight and height in a sample of adolescents attending secondary school in the region of Lazio. Among the studied socio-demographic factors, gender, school municipality, mother's employment status, and family structure had a significant effect on this prevalence. These findings show a high prevalence of body weight excess associated with sociodemographic factors in the Italian sample investigated, and the need for effective public health interventions to combact obesity with particular attention to disadvantaged adolescents. Global actions should be implemented at all levels involving all sectors of the community, from the context of the school, to the family and health, for greater amplification and effectiveness of the results. These interventions, based on education and information strategies to reach adolescents such as web-based technologies and mobile apps, should be multicomponent combining the many aspects of lifestyle. A Surveillance System of the Italian Adolescents should be implemented through anthropometric measurement data to monitor the effectiveness of the policies to counteract obesity.

\section{Acknowledgement}

The authors gratefully thank the teachers, adolescents and families who participated in this study.

\section{Conflict of Interests}

None declared

\section{Funding}

Funding for this study was made possible by the financial support of the Ministry of Agriculture, Food and Forestry (MAFF).

\section{Ethical Approval}

The study was conducted according to the guidelines laid down in the Declaration of Helsinki and all procedures involving human subjects were approved by the Ethics Committee of the National Research Institute on Food and Nutrition, Rome, Italy.

\section{REFERENCES}

1. World Health Organization. Global strategy on diet, physical activity and health. Childhood overweight and obesity [Internet]. Geneva: WHO; 2012 [cited 2016 Nov 30]. Available from: http://www.who.int/dietphysicalactivity/childhood/en/.

2. Vereecken CA, Todd J, Roberts C, Mulvihill C, Maes L. Television viewing behaviour and associations with food habits in different countries. Public Health Nutr. 2006 Apr;9(2):244-50. 
3. Eichen DM, Conner BT, Daly BP, Fauber RL. Weight perception, substance use, and disordered eating behaviors: comparing normal weight and overweight high-school students. J Youth Adolesc. 2012 Jan;41(1):1-13.

4. Rafraf M, Gargari BP, Safaiyan A. Prevalence of prehypertension and hypertension among adolescent high school girls in Tabriz, Iran. Food Nutr Bull. 2010 Sep;31(3):461-5.

5. Liou YM, Liou TH, Chang LC. Obesity among adolescents: sedentary leisure time and sleeping as determinants. J Adv Nurs. 2010 Jun;66(6):124656.

6. Newell A, Zlot A, Silvey K, Arail K. Addressing the obesity epidemic: a genomics perspective. Prev Chronic Dis. 2007 Apr;4(2):A31.

7. Chou YC, Pei JS. Risk Factors of Adolescent Obesity in Taiwan and its association with physical activity, blood pressure and waist circumference. Asian J Sports Med. 2010 Dec;1(4):214-22.

8. Ozier AD, Kendrick OW, Leeper JD, Knol LL, Perko M, Burnham J. Overweight and obesity are associated with emotion- and stress-related eating as measured by the eating and appraisal due to emotions and stress questionnaire. J Am Diet Assoc. 2008 Jan;108(1):49-56.

9. Ogden CL, Carroll MD, Kit BK, Flegal KM. Prevalence of childhood and adult obesity in the United States, 2011-2012. JAMA. 2014 Feb 26;311(8):806-14

10. Ogden CL, Carroll MD, Flegal KM. High body mass index for age among US children and adolescents, 2003-2006. JAMA. 2008 May 28;299(20):2401-5.

11. Wijnhoven TM, van Raaij JM, Spinelli A, Starc G, Hassapidou M, Spiroski I, et al. WHO European Childhood Obesity Surveillance Initiative: body mass index and level of overweight among 6-9-year-old children from school year 2007/2008 to school year 2009/2010. BMC Public Health. 2014 Aug 7;14:806. doi: 10.1186/1471-2458-14-806.

12. Lobstein T, Baur L, Uauy R; IASO International Obesity TaskForce. Obesity in children and young people: a crisis in public health. Obes Rev. 2004 May; 5 Suppl 1:4-104.

13. Low S, Chin MC, Deurenberg-Yap M. Review on epidemic of obesity. Ann Acad Med Singapore. 2009 Jan;38(1):57-9.

14. Currie C, Zanotti C, Morgan A; WHO Regional Office for Europe. Social determinants of health and well-being among young people. Health Behaviour in School-Aged Children (HBSC) Study: International Report from the 2009/2010 Survey. Health Policy for Children and Adolescents, No. 6. Copenhagen: WHO Regional Office for Europe; 2012.

15. Lazzeri G, Giacchi MV, Spinelli A, Pammolli A, Dalmasso P, Nardone P, et al. Overweight among students aged $11-15$ years and its relationship with breakfast, area of residence and parents' education: results from the Italian HBSC 2010 cross-sectional study. Nutr J. 2014 Jul 5;13:69. doi: 10.1186/1475-2891-13-69.

16. Bennett S, Woods T, Liyanage WM, Smith DL. A simplified general method for cluster-sample surveys of health in developing countries. World Health Stat Q. 1991;44(3):98-106.

17. Physical status: the use and interpretation of anthropometry. Report of a WHO Expert Committee. World Health Organ Tech Rep Ser. 1995;854:1452.

18. Cole TJ, Lobstein T. Extended international (IOTF) body mass index cut-offs for thinness, overweight and obesity. Pediatr Obes. 2012 Aug;7(4):284-94

19. de Onis M, Onyango AW, Borghi E, Siyam A, Nishida C, Siekmann J. Development of a WHO growth reference for school-aged children and adolescents. Bull World Health Organ. 2007 Sep;85(9):660-7.

20. Blössner M, Siyam A, Borghi E, Oniango A, de Onis M. WHO AnthroPlus for personal computers manual: software for assessing growth of the world's children and adolescents [Internet]. Geneva: WHO; 2009 [cited 2016 Nov 30]. Available from: http://www.who.int/growthref/ tools/who_anthroplus_manual.pdf.

21. Rolland-Cachera MF. Childhood obesity: current definitions and recommendations for their use. Int J Pediatr Obes. 2011 Oct;6(5-6):325-31.

22. Maffeis C, Banzato C, Talamini G; Obesity Study Group of the Italian Society of Pediatric Endocrinology and Diabetology. Waist-to-height ratio, a useful index to identify high metabolic risk in overweight children. J Pediatr. 2008 Feb;152(2):207-13.
23. Katzmarzyk PT, Shen W, Baxter-Jones A, Bell JD, Butte NF, Demerath EW, et al. Adiposity in children and adolescents: correlates and clinical consequences of fat stored in specific body depots. Pediatr Obes. 2012 Oct;7(5):e42-61.

24. Browning LM, Hsieh SD, Ashwell M. A systematic review of waist-toheight ratio as a screening tool for the prediction of cardiovascular disease and diabetes: 0.5 could be a suitable global boundary value. Nutr Res Rev. 2010 Dec;23(2):247-69.

25. HBSC Italy. Lifestyle and health of youth in school age. Report. Regional data HBSC 2009-2010 Region Lazio [Internet]. [cited 2016 May 23]. Available from: http://www.hbsc.unito.it/it/images/pdf/hbsc/ report_lazio_hbsc_2010.pdf.

26. Savva SC, Tornaritis M, Savva ME, Kourides Y, Panagi A, Silikiotou N, et al. Waist circumference and waist-to-height ratio are better predictors of cardiovascular disease risk factors in children than body mass index. Int J Obes Relat Metab Disord. 2000 Nov;24(11):1453-8.

27. Brambilla P, Bedogni G, Moreno LA, Goran MI, Gutin B, Fox KR, et al. Crossvalidation of anthropometry against magnetic resonance imaging for the assessment of visceral and subcutaneous adipose tissue in children. Int J Obes (Lond). 2006 Jan;30(1):23-30.

28. Li C, Ford ES, Mokdad AH, Cook S. Recent trends in waist circumference and waist-height ratio among US children and adolescents. Pediatrics. 2006 Nov;118(5):e1390-8.

29. Veldhuis L, Vogel I, Jansen W, Renders CM, HiraSing RA, Raat H. Moderate agreement between body mass index and measures of waist circumference in the identification of overweight among 5-year-old children; the 'be active, eat right' study. BMC Pediatr. 2013 Apr 23;13:63. doi: 10.1186/1471-2431-13-63.

30. Hesketh K, Crawford D, Salmon J, Jackson M, Campbell K. Associations between family circumstance and weight status of Australian children. Int J Pediatr Obes. 2007;2(2):86-96.

31. Klein-Platat C, Wagner A, Haan MC, Arveiler D, Schlienger JL, Simon C Prevalence and sociodemographic determinants of overweight in young French adolescents. Diabetes Metab Res Rev. 2003 Mar-Apr;19(2):153-8.

32. Rasmussen F, Johansson M. The relation of weight, length and ponderal index at birth to body mass index and overweight among 18-year-old males in Sweden. Eur J Epidemiol. 1998 Jun;14(4):373-80.

33. Júlíusson PB, Eide GE, Roelants M, Waaler PE, Hauspie R, Bjerknes R. Overweight and obesity in Norwegian children: prevalence and sociodemographic risk factors. Acta Paediatr. 2010 Jun;99(6):900-5.

34. Phipps SA, Lethbridge L, Burton P. Long-run consequences of parental paid work hours for child overweight status in Canada. Soc Sci Med. 2006 Feb;62(4):977-86.

35. Morrissey TW, Dunifon RE, Kalil A. Maternal employment, work schedules, and children's body mass index. Child Dev. 2011 JanFeb;82(1):66-81.

36. Binkin N, Fontana G, Lamberti A, Cattaneo C, Baglio G, Perra A, et al. A national survey of the prevalence of childhood overweight and obesity in Italy. Obes Rev. 2010 Jan;11(1):2-10.

37. Shrewsbury V, Wardle J. Socioeconomic status and adiposity in childhood: a systematic review of cross-sectional studies 1990-2005. Obesity (Silver Spring). 2008 Feb;16(2):275-84.

38. Brophy S, Cooksey R, Gravenor MB, Mistry R, Thomas N, Lyons RA, et al. Risk factors for childhood obesity at age 5: analysis of the millennium cohort study. BMC Public Health. 2009 Dec 16;9:467. doi: 10.1186/14712458-9-467.

39. Sobal J. Obesity and socioeconomic status: a framework for examining relationships between physical and social variables. Med Anthropol. 1991 Sep;13(3):231-47.

40. Sjöberg A, Moraeus L, Yngve A, Poortvliet E, Al-Ansari U, Lissner L. Overweight and obesity in a representative sample of schoolchildren - exploring the urban-rural gradient in Sweden. Obes Rev. 2011 May;12(5):305-14

Received March 30, 2015 Accepted in revised form May 23, 2016 